\title{
COMMENTARY
}

\section{Arterial pressure optimization in the treatment of septic shock: a complex puzzle}

\author{
Alan E Jones', Stephen Trzeciak ${ }^{2}$ and R Phillip Dellinger*3 \\ See related research by Dunser et al., http://ccforum.com/content/13/6/R181
}

\begin{abstract}
Arterial pressure optimization in septic shock is a critical, yet poorly understood component of resuscitation. New data suggest that, during the routine management of patients with severe sepsis, there is no association between mean arterial pressure achieved and outcome as long as the mean arterial pressure is maintained at or above $70 \mathrm{mmHg}$. Although these data add important new evidence to our understanding of arterial pressure management, there are still many unanswered questions upon which future investigations should focus.
\end{abstract}

In the previous issue of Critical Care Dunser and colleagues presented the results of post-hoc analysis that add another piece to the puzzle of understanding optimal arterial pressure goals in the treatment of sepsis [1]. The authors examine data from a control group of severe sepsis patients enrolled in an interventional trial that mandated hemodynamic management to specific therapeutic targets, one of which was achievement of a mean arterial pressure (MAP) of $70 \mathrm{mmHg}$ or higher through the use of vasopressors. Dunser and colleagues analyzed the association between the average MAP, both as a continuous variable and grouped into quartiles, and mortality. What they found was no association between average MAP, or MAP quartiles above $70 \mathrm{mmHg}$, and 28-day mortality. They did, however, report an association between vasopressor load and mortality.

In his classic text Physiology of Shock published in 1950, Dr Carl J Wiggers wrote 'In short, there are no pathognomonic signs of shock ... The instability of a patient's

*Correspondence: dellinger-phil@cooperhealth.edu

${ }^{3}$ Division of Critical Care Medicine, Cooper University Hospital, One Cooper Plaza D393, Camden, NJ 08103, USA

Full list of author information is available at the end of the article condition, along with progressive deterioration, constitutes the best evidence of shock. In the assessment of such determination, the trend of arterial pressures remains one of our best criteria' [2]. For over a century, arterial hypotension has been intensely studied as a central cause of organ hypoperfusion and subsequent organ injury in critically ill patients. This includes patients with hemorrhage [2], heterogeneous populations of prehospital patients [3] and emergency department patients [4], and specific disease states such as pulmonary embolism [5], acute myocardial infarction [6], postcardiac arrest syndrome [7], and sepsis [8]. Because of both the universal availability of its measurement and its association with severity of illness, medical care providers frequently use blood pressure to communicate with each other about the hemodynamic stability of patients.

We agree with the authors' contention that consensus recommendation of a goal for MAP as a therapeutic target in septic shock management is more or less an arbitrary number that represents a minimal threshold that experts would consider clinically acceptable [9]. One randomized controlled trial for the resuscitation of patients with sepsis used a MAP of $65 \mathrm{mmHg}$ or higher as a goal for hemodynamic support; however, the MAP goal was part of the interventional algorithm for both arms of the trial (that is, treatment and control) and therefore MAP was effectively removed from the experiment [10]. The data presented in Dunser and colleagues' study are important and allow the conclusion that, during routine management of patients with severe sepsis, there is no association between MAP achieved and outcome as long as the MAP is maintained at or above $70 \mathrm{mmHg}$.

It is important to note in this study, however, that a MAP of $70 \mathrm{mmHg}$ was not tested as a threshold or target for hemodynamic support. This would have required an investigation in which patients were assigned to different MAP thresholds as therapeutic targets (for example, $60 \mathrm{mmHg}, 65 \mathrm{mmHg}, 70 \mathrm{mmHg}$, and so forth) and outcomes were compared between these groups. No such large-scale definitive study has been performed to date. 
We are therefore left to manage patients with consensus recommendations and our best clinical judgment.

Another important point of discussion of Dunser and colleagues' report centers on a secondary finding. They conclude that their data indicate an association between vasopressor load and both mortality and disease-related events. Intuitively this makes sense: the more vasopressor support a patient requires, the more severely ill the patient is and thus the more likely the patient is to suffer either drug or disease-related morbidity and mortality. These data do not, however, allow the conclusion stated in their paper - that elevating MAP $>70 \mathrm{mmHg}$ by augmenting vasopressor dosages may increase mortality. This conclusion would require an experimental design that allowed testing of cause and effect rather than an analysis of association. In our opinion, a more likely reason for the association between higher vasopressor doses and poor outcome would be some combination of more refractory sepsis-induced vasodilation and lower cardiac output, both assumed to be linked to poorer prognosis. An important consideration as it relates to vasopressor therapy is being constantly vigilant in minimizing vasopressor dosage by targeting the lowest pressure that can be assured to be providing adequate tissue perfusion while assuring that additional volume infusion - or, in some patients, inotropic therapy - will allow reduction of vasopressor therapy.

There are many factors about the cardiovascular support of sepsis that remain relatively unknown. Although arterial blood pressure is important and is clearly associated with outcome, the overarching goal of cardiovascular support is to optimize blood flow to tissues. The relationship between arterial pressure and flow is complex and incompletely understood [11]. There is possibly also no single optimal MAP that can be applied to all sepsis patients, as patient-specific factors are probably extremely important in determining patient response. Pre-existing disease, intact autoregulation and distribution of flow, among other factors, all play a role in the optimal MAP level an individual patient needs in order to achieve optimal outcomes.

Let us suppose for a moment that an optimal MAP for sepsis cardiovascular support was clearly identified, associated with improved outcomes, and widely accepted and utilized in clinical care. While a critical piece of the sepsis puzzle would be filled, many others would still be missing - such as the optimal time frame in which the goal should be reached, the optimal therapeutic methods to achieve the goal (for example, fluids, vasopressors), and how long the goal must be maintained. So it appears that the more we learn about cardiovascular support in sepsis, the less we actually know.

\section{Abbreviations}

MAP $=$ mean arterial pressure.

\section{Author details}

'Department of Emergency Medicine, Carolinas Medical Center, 1000 Blythe Blvd, Charlotte, NC, 28203, USA.

2Division of Critical Care Medicine, Departments of Medicine and Emergency Medicine, Cooper University Hospital, One Cooper Plaza D393, Camden, NJ 08103, USA.

3Division of Critical Care Medicine, Department of Medicine, Cooper University Hospital, One Cooper Plaza D393, Camden, NJ 08103, USA.

\section{Competing interests}

The authors declare that they have no competing interests.

Published: 19 January 2010

\section{References}

1. Dunser MW, Ruokonen E, Pettila V, Ulmer H, Torgersen C, Schmittinger CA, Jakob S, Takala J: Association of arterial blood pressure and vasopressor load with septic shock mortality: a post hoc analysis of a multicenter trial. Crit Care 2009, 13:R181.

2. Wiggers C: Physiology of Shock. London: The Commonwealth Fund; 1950.

3. Jones A, Stiell I, Nesbitt L, Spaite D, Hasan N, Watts B, Kline JA: Nontraumatic out-of-hospital hypotension predicts in-hospital mortality. Ann Emerg Med 2004, 43:106-113.

4. Jones $A E$, Yiannibas V, Johnson CL, Kline JA: Emergency department hypotension predicts sudden unexpected in-hospital mortality: a prospective cohort study. Chest 2006, 130:941-946.

5. Goldhaber S, Visani L, De Rosa M: Acute pulmonary embolism: clinical outcomes in the International Cooperative Pulmonary Embolism Registry (ICOPER). Lancet 1999, 353:1386-1389.

6. Lee K, Woodlief L, Topol E, Weaver W, Betriu A, Col J, Simoons M, Aylward P, Van de Werf F, Califf RM: Predictors of 30-day mortality in the era of reperfusion for acute myocardial infarction. Results from an international trial of 41,021 patients. GUSTO-I Investigators. Circulation 1995, 91:1659-1668.

7. Trzeciak S, Jones AE, Kilgannon JH, Milcarek B, Hunter K, Shapiro NI, Hollenberg SM, Dellinger P, Parrillo JE: Significance of arterial hypotension after resuscitation from cardiac arrest. Crit Care Med 2009, 37:2895-2903.

8. Marchick MR, Kline JA, Jones AE: The significance of non-sustained hypotension in emergency department patients with sepsis. Intensive Care Med 2009, 35:1261-1264.

9. Dellinger RP, Levy MM, Carlet JM, Bion J, Parker MM, Jaeschke R, Reinhart K, Angus DC, Brun-Buisson C, Beale R, Calandra T, Dhainaut JF, Gerlach H, Harvey M, Marini JJ, Marshall J, Ranieri M, Ramsay G, Sevransky J, Thompson BT, Townsend S, Vender JS, Zimmerman JL, Vincent J-L: Surviving sepsis campaign: international guidelines for management of severe sepsis and septic shock: 2008. Crit Care Med 2008, 36:296-327.

10. Rivers E, Nguyen B, Havstad S, Ressler J, Muzzin A, Knoblich B, Peterson E, Tomlanovich M: Early goal-directed therapy in the treatment of severe sepsis and septic shock. N Engl J Med 2001, 345:1368-1677.

11. Trzeciak S, Cinel I, Dellinger RP, Shapiro NI, Arnold RC, Parrillo JE, Hollenberg SM: Resuscitating the microcirculation in sepsis: the central role of nitric oxide, emerging concepts for novel therapies, and challenges for clinical trials. Acad Emerg Med 2008, 15:399-413.

doi:10.1186/cc8194

Cite this article as: Jones $A E$, et al.: Arterial pressure optimization in the treatment of septic shock: a complex puzzle. Critical Care 2010, 14:102. 